\title{
The EFSUMB website, a guide for better understanding
}

\author{
Christoph F. Dietrich ${ }^{1}$, Lynne Rudd ${ }^{2}$
}

${ }^{1}$ Med. Klinik 2, Caritas-Krankenhaus Bad Mergentheim, Germany, ${ }^{2}$ EFSUMB office, 28 Portland Place, London W1B 1LY UK

\begin{abstract}
The aim of the paper is to introduce readers to EFSUMB's wide ranging activities which have embraced modern technology. The most recent is the Atlas www.efsumb-atlas.org primarily introduced to accompany the Elastography, CEUS Liver and Non Liver Guidelines but intended to expand to all areas to offer a database of images which can be freely downloaded. Hosting eBooks on our website is another new departure, most importantly the EFSUMB Course Book on Ultrasound which is also in a printed form but allowing chapters to be updated online, an online Student Edition of the ECB to be launched at EUROSON 2013. EFSUMB has been active with updating Guidelines; those mentioned above have all been revised or written in the last two years. The EFSUMB Newsletter in the EJU promotes our activities and topical articles intended to reach all our members with the mailing of Issue 1. The Case of the Month continues to be one of EFSUMB's most visited sites and in the last few years has been translated into seven different languages including Chinese. In conclusion this article aims to provide a guide to the website educational sites of the European Federation of Societies for Ultrasound in Medicine and Biology (EFSUMB).
\end{abstract}

Keywords: EFSUMB, website, educational sites, guidelines, recommendation

\section{Introduction}

This article aims to provide a guide to the website educational sites.

\section{A short history of EFSUMB}

In 1972, the delegates of 13 European ultrasound societies met in Basel, Switzerland for the formal foundation of the European Federation of Societies for Ultrasound in Medicine and Biology (EFSUMB). Today the Federation comprises 29 National Societies with almost 20,000 members which means EFSUMB is the largest Society within the World Federation for Ultrasound in Medicine and Bi-

Received 14.06.2013 Accepted 27.06.2013

Med Ultrason

2013, Vol. 15, No 3, 215-223

Corresponding author: Prof. Dr. Christoph F. Dietrich

Med. Klinik 2

Caritas-Krankenhaus Bad Mergentheim

Uhlandstr. 7, 97980 Bad Mergentheim

Tel.: +49-7931-58-2201, Fax: +49-7931-58-2290

Email: christoph.dietrich@ckbm.de ology (WFUMB). The European Federation's purpose has been to promote the exchange of scientific knowledge in the field of ultrasound. The Federation proposes standards and gives advice concerning criteria for the optimalisation of scanners, of techniques, and concerning presentation and interpretation of results. These aims are to be served by arrangement of congresses, meetings and courses at an international level, as well as the exchange of information both in and outside Europe by the member organisations. EFSUMB has strengthened the interdisciplinary collaboration in the field of diagnostic ultrasound and promoted safety of ultrasound in medical use [1-7].

Among other activities EFSUMB has published Guidelines for the use of contrast agents in ultrasound plus proposed minimal training requirements for the practice of medical ultrasound in Europe [www.efsumb.org]. These identify three levels of training and expertise [8]. The boundaries between the three levels are difficult to define precisely and should be regarded as a guide to different levels of competence and experience. 


\section{Current activities}

The aim of the paper is to introduce readers to EFSUMB's wide ranging activities which have embraced modern technology $[6,9]$. The most recent is the Atlas www.efsumb-atlas.org, primarily introduced to accompany the Elastography $[10,11]$, Contrast Enhanced Ultrasound (CEUS) Liver [12] and Non Liver Guidelines [13] as well as dynamic contrast enhanced ultrasound [14] but intended to expand to all areas to offer a database of images which can be freely downloaded. Comments have been published as well [15-23]. Hosting eBooks on our website is another new departure, most importantly the EFSUMB Course Book on Ultrasound (ECB) which is also in a printed form but allowing chapters to be updated online, an online Student Edition of the ECB to be launched at EUROSON 2013 and followed up as an electronic publication for easy distribution and sale from the website. Other eBooks online are Safe Use of Ultrasound in Medical Diagnosis and the much viewed Hepatic Elastography Using Ultrasound Waves. EFSUMB has been active with updating Guidelines; those mentioned above have all been revised or written in the last two years. The EFSUMB Newsletter edited by Adrian Săftoiu, in the Ultraschall in der Medizin / European Journal of Ultrasound (EJU), promotes our activities and topical articles [24-26] intended to reach all our members with the mailing of Issue 1, however we do not always receive the mailing addresses from some of the national societies.

The Case of the Month [27,28] continues to be one of EFSUMB's most visited sites and in the last few years has been translated into seven different languages including Chinese. The website shows all the current EUROSON Schools, those courses endorsed by EFSUMB which are held in the national language, forthcoming congresses and other related ultrasound events which are listed in the calendar.

Recordings have been made of some of the CEUS Schools and EFSUMB has introduced postgraduate web courses for those interested in testing their understanding still further. Continuing Medical Education (CME) is of interest to many of our viewers where this is a requirement in some countries. The Education and Professional Standards Committee (EPSC) has proposed the EFSUMB CME credits for such studies, compatible with national credits in value which it is hoped will be recognized by the National Societies. We urge all recipients of the EFSUMB CME credits to contact the accreditation organization in their country to accept these credits.

\section{An introduction into the EFSUMB website Lay out}

The new look EFSUMB website horizontal panel with have the following headings: About EFSUMB -
Courses and Congresses - Case of the Month - Atlas Educational - Publication - Research. An innovation is the Research link, which it is hoped will offer financial incentives to younger members to attend Congresses, to advertise the Young Investigator Award and be an area for information for the Education Committee project of Ultrasound Learning Centres where participating hospitals can offer exchange programmes for those interested in learning ultrasound. The sub headings mostly remain unchanged, as well as the calendar with EFSUMB and non-EFSUMB events listed, but with a month's listed events automatically opening when that month is viewed.

Our blog has had 14,501 hits in the last three months but by showing the comments, we hope this will become more interactive. To help those new to the site the search facility button will be more prominent. EFSUMB is responding to users requests and changing needs. The Publication Committee spearheaded the adaptation of the website for viewing with mobile phones and iPads.

\section{Statistics}

EFSUMB carefully monitors the website viewing statistics. Responding to our viewing audience, we have introduced Case of the Month translations to encourage and assist our viewers. Before the publication of the EFSUMB Course Book on Ultrasound online the website viewing figures were very modest. In 2008 around 29,700 visitors, but coinciding with the ECB online the visitors leapt to 177,000 and in the last 12 months we have maintained these figures. The Case of the Month is still the most visited page, followed by the events calendar and the ECB.

\section{Guidelines}

\section{History}

Over the last decade EFSUMB has produced a series of Guidelines and Recommendations. The EPSC, EFSUMB's Education Committee has produced Minimum Training Recommendations in various specialities. There are Guidelines and Safety Statements from ECMUS, EFSUMB's Safety Committee.

In addition, EFSUMB has made recommendations for the performance and reporting of US examinations in portal hypertension [29,30]. The CEUS Liver Guidelines, 2012 was a joint WFUMB/EFSUMB publication updating the 2008 [9] and 2004 [6], CEUS non Liver Guidelines, 2011 [13] updating the 2004 Guidelines [6] and has published the first Elastography Guidelines, $2012[10,11]$.

\section{Detailed description}

The most recent Minimum Training Recommendations are in Rheumatology, Interventional US, CEUS, 
Musculoskeletal, Thoracic US, Vascular and EUS. To date there are 15 different Appendixes on the website. The Recommendations usually list three levels of attainment with the theoretical and practical training for each level and list the competencies that should be acquired at each level. Maintenance of skills is also considered and suggestions are made. Training competency assessment sheets are provided in most cases.

The Safety Statements are updated regularly and the most recent are the Clinical Safety Statement for Diagnostic Ultrasound, 2011 and the EFSUMB Statement on the Safe use of Doppler Ultrasound during Scans at $11-14$ weeks (or earlier in pregnancy) 2013. ECMUS reviews the statements produced by AIUM, ISUOG and WFUMB to ensure that there is standardisation in the information available. The Souvenir Scanning Statement and EFSUMB Statement On The Safe Use Of Doppler Ultrasound During Scans At 11-14 Weeks (Or Earlier In Pregnancy) 2013 are examples of common statements.

The Guidelines and Good Clinical Practice Recommendations for Contrast Enhanced Ultrasound (CEUS) in the Liver - Update 2012 [12] is freely available to download from the EFSUMB website and the Atlas has images to illustrate them. These guidelines and recommendations provide general advice on the use of all currently clinically available ultrasound contrast agents (UCA). They are intended to create standard protocols for the use and administration of UCA in liver applications on an international basis and improve the management of patients worldwide.

The EFSUMB Guidelines and Recommendations on the Clinical Practice of Contrast Enhanced Ultrasound (CEUS): Update 2011 on non-hepatic applications [13] aims to explain the rationale for proceeding with the investigation, reports on the extremely rare and limited risks to which patients are exposed when they undergo a CEUS examination and attempts to provide a recommendation level for each indication.

The EFSUMB Guidelines and Recommendations on the Clinical Use of Ultrasound Elastography Part 1: Basic Principles and Technology provides an introduction to the physical principles and technology on which all forms of current commercially available ultrasound elastography are based [11]. The practical advantages and disadvantages associated with each of the techniques are described and guidance is provided on optimisation of scanning technique, image display, image interpretation and some of the known image artefacts. Images illustrating the Guidelines are available on the Atlas and can be freely downloaded. [See Fig 3 for the Atlas Submission Template for submitting your images.]

\section{EFSUMB Course Book (ECB) \\ Short introduction}

There is a need to incorporate ultrasound experience into clinical courses and accreditation. This new multidisciplinary Course Book is intended to complement and advance the educational purposes of EFSUMB in a modern way, and will integrate the extensive experience of European authors and ultrasound teachers [31]. The course book is devoted to the interdisciplinary approach of the multinational societies of EFSUMB. It is the intention to distribute the ECB all over Europe and also to standardize and improve examination techniques. Furthermore, the ECB is aiming at illustrating and supporting the EFSUMB course system and the well established EUROSON schools. In addition, the ECB incorporates the minimum training recommendations for the practice of medical ultrasound published by EFSUMB.

The book has been prepared in close collaboration with the EFSUMB Publication and Education Committees and is already published on the new Educational Portal (http://www.efsumb-portal.org/ep). All chapters will be updated on a regular basis. Additionally, examination technique videos are published on our website [www.efsumb.org]. Please, do not hesitate to send your comments and we would also welcome additional contributions including videos (which might also be published as the Case of the Month [See Fig 2 for the Template]). Finally, we hope that this new achievement in ultrasound education will stimulate and nurture your own knowledge and well serve the whole European ultrasound community.

\section{Aim of the book}

The EFSUMB Course Book (ECB) is intended to supplement and complete the educational purposes of EFSUMB. The book has been published on the website in close collaboration with the EFSUMB Publication and Education committees.

The aim is to distribute the ECB all over Europe, by offering the book for sale from the EFSUMB website at a heavily subsidized price or offering free downloads, to standardize and improve examination techniques and to illustrate the EFSUMB course system.

Where to find and how to use the ECB on the EFSUMB website

The chapters are listed on the website which is accessed from the main menu. The videos accompanying the chapters are listed separately, as well as embedded in the chapters. Observant viewers will notice that not all the chapters in the book are available in the website version and vice versa. Some chapters were not available for the 2012 publication but are now online, such as the chapters on Liver Transplantation and Ultrasound in tropical medicine. Human Immunodeficiency Virus (HIV) Infection. 


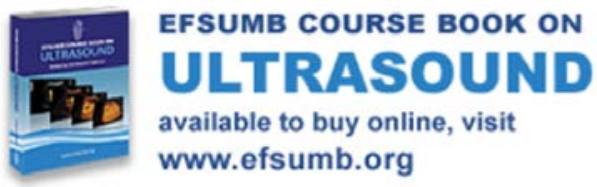

Fig 1. ECB available for purchase online

\section{Download chapters/why}

Any general ultrasound textbook is going to cover aspects which are not relevant to every clinician. An online version offers the opportunity to read those chapters of interest and the facility to print them. The advantage of an online version is to be able to view the videos of both examination techniques and images which are hosted on YouTube, and again can be downloaded for use in lectures or teaching. Most importantly the information can be updated in what is one of the most rapidly advancing fields of medicine.

\section{Printed version/why}

For those clinicians improving their ultrasound skills the ECB is a valuable learning tool which is always to hand. For the teachers of ultrasound the book offers a structure for course teaching with images for reference. EFSUMB hopes that organizers of ultrasound schools will consider purchasing the ECB at a further discounted rate rather than printing material to accompany courses which is costly and time consuming (fig 1). Contact efsumb@efsumb.org for bulk book purchases.

\section{Work in progress, how can one contribute?}

The ECB editor invites comments on the chapters and where information has been updated this is requested so that the online chapters can take this into account. EFSUMB can be contacted by email via the website or the editor contacted directly at the address shown above. The EFSUMB blog is another way of commenting on topics and is a forum for exchange of ideas or inviting comments from colleagues. The book is in no way exhaustive of topics, for example there is no chapter on Musculoskeletal but the hard copy had to take into account the number of pages a paperback version could accommodate. However the website can host further chapters and if you consider there are important omissions please contact the editor with suggested topics and authors.

EFSUMB Course Book, Student Edition (ECBSE)

The EPSC felt that a version of the ECB should be made accessible for students, hence the ECBSE. Less detail and more pathology was considered necessary with fewer images restricted to showing a healthy organ and a diseased organ. Examination technique videos are very necessary for students and the aim is to produce a version within the year considering these criteria. In addition to Prof Christoph F Dietrich, an additional two editors are involved - Ass Prof Jan Tuma and Prof Radu Badea and they are inviting the authors of the original chapters to tailor the chapters to students' needs. The ESBSE will be available on the EFSUMB website but under consideration is an electronic version of the book, such as a DVD, or USB stick or even an app so that the 'book' could be offered at the lowest possible price, be easily mailed to those who would like a permanent version and be easily transportable to a Congress or Schools.

Why US learning for students, aim

The EPSC is of the opinion that it is very important that medical students are trained in the principles of diagnostic ultrasound. Ultrasound can be a very valuable tool not just in diagnostics but also in enabling students to understand anatomy and physiology. In many instances it can replace the need for dissection. The Committee is endeavouring to assess the variability of time that is devoted to ultrasound education for medical students around Europe and to get a fuller picture of these variations. The course book would be a useful handbook for teachers of ultrasound with a core syllabus that would ensure uniform education for all students.

\section{How to use website to find chapters}

The ECBSE will be hosted on the Educational Portal of the website under the icon ECBSE and the chapters will be listed in the same manner as for the ECB. The order will not follow that of the printed book as certain chapters of a more advanced nature will not be included.

\section{How to find videos}

Videos and images will be embedded in the chapters with an additional first chapter, $\mathrm{Ch} 00$ listing the videos for quick reference to the procedure, without the need to search through the text.

\section{Work in progress, how can one contribute?}

The Editors welcome video clips of examination techniques, images and written contributions which can be sent via Mailbigfile which is a link from the main menu under Contact. Alternatively contact efsumb@ efsumb.org for the Dropbox access. Again the blog is a useful way to make any shorter comments or to point out any inconsistencies. Our blog administrator Dr Luca Sconfienza invites discussion on topics on the EFSUMB website or on ultrasound issues that you feel need to be raised with a wider audience.

\section{Case of the month (CoM)}

\section{Short history}

The Cases of the month (CoM) have been introduced by Christoph F. Dietrich as first Editor from 2008 to 2011 


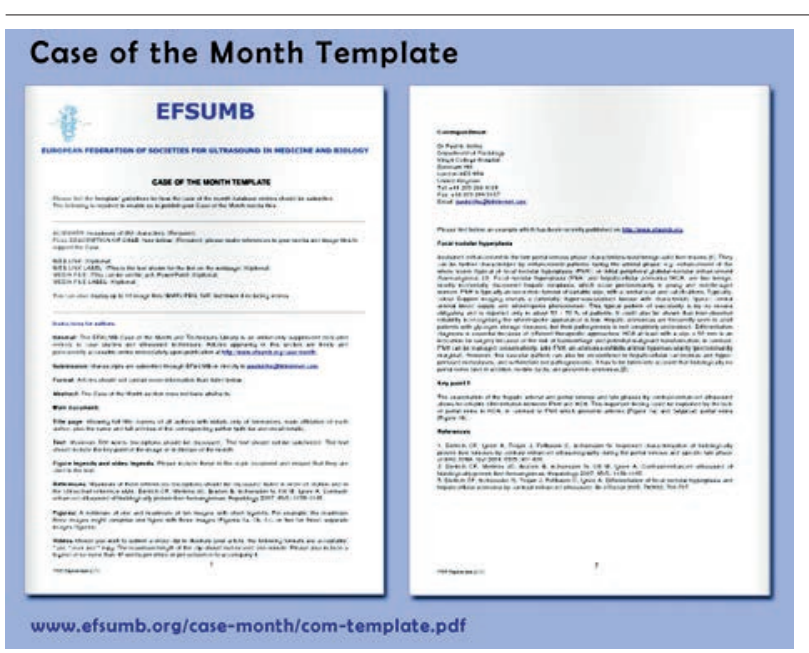

Fig 2. Case of the Month Submission Template.

[27] followed by Paul Sidhu [28]. The earliest case of the month went online in March 2008. The Publication Committee envisaged regular contributions to include artefact of the month, tip of the month in addition to cases that would be of interest. Since this first case there been eight cases published in 2008, six cases in 2009, four cases in 2010, nine cases in 2011, eight cases in 2012 and five to date in 2013. Topics have ranged from Crohn's disease, Echoscopy, to a rare double gallbladder. All these cases are listed on the EFSUMB website under http://efsumb. org/case-month/case-archive.asp.

The translations into seven foreign languages can all be accessed from this page. If you would like to translate any of the cases please contact Paul Sidhu or if you wish to submit a Case of the Month resource to EFSUMB for consideration email Paul.Sidhu@efsumb.org (Contact: Prof Paul S. Sidhu, Department of Radiology, King's College Hospital, Denmark Hill, London SE5 9RS, United Kingdom, Tel: +44 203299 4164, Fax: +44 203 299 3157, Email: Paul.Sidhu@efsumb.org or efsumb@ efsumb.org

Atlas

Aim

An image can say more than a thousand words; and an image plus an adequate number of words provides the most effective information. This is why EFSUMB decided to set up an atlas of images to illustrate its Clinical Recommendations and Guidelines, which as of 2013 include a variety of contrast enhanced ultrasound and elastographic applications. These recommendations have been regularly published in Ultraschall in der Medizin / European Journal of Ultrasound (EJU) in recent years (and can be downloaded for free from the EFSUMB website) and will be updated by future editions; however, due to printed space limits, such articles do not include clinical images. In the Atlas you can now find pictures and video clips illustrating the typical patterns of most of the ultrasound findings described in the guidelines, whose display is indexed according to the structure of the guidelines, to allow an easy and rapid access directly to the topic of your interest. We are confident that visiting these web pages will be a highly fruitful time for your professional activity, whatever the field of ultrasound applications you are involved in.

\section{Explanation about Atlas}

The Atlas is currently divided in three sections, CEUS Liver Guidelines, CEUS Non Liver Guidelines and Elastography.

The Guidelines and Good Clinical Practice Recommendations for Contrast Enhanced Ultrasound (CEUS) in the Liver - Update 2012 a joint WFUMB/EFSUMB document describes the third iteration of recommendations for the hepatic use of contrast enhanced ultrasound (CEUS) and contrast specific imaging techniques introduced ten years ago in Europe and Canada. Dynamic contrast enhanced ultrasound has been published by EFSUMB. The Atlas is divided into focal liver lesions in the cirrhotic and non cirrhotic liver and then subdivided into benign and malignant liver lesions. These categories are then further subdivided. In these categories the images are located either singly or as multiple images.

The EFSUMB Guidelines and Recommendations on the Clinical Practice of Contrast Enhanced Ultrasound (CEUS): Update 2011 on non-hepatic applications has been published as a full-text in the European Journal of Ultrasound / Ultraschall in der Medizin. A need for an updated atlas which contains images and videos of nonliver CEUS applications was considered necessary as it will be a useful instrument and continuous inspiration during usage of the guidelines in daily routine clinical work-up. The non-liver CEUS part of the atlas is structured with the same sub-categories as the full guidelines published on the EFSUMB website. All the organs are listed but not all categories are filled. The Atlas administrator invites images and videos submitted via the EFSUMB website using the submission template shown below (fig 3). This is the only way to ensure the highest standards of accuracy.

Elastography is a single word, but includes a great variety of different techniques, which are differently suited for various applications, even in the same organ [32-34].

The modality by which various techniques are applied may substantially differ and accordingly also the type of findings may be completely different using different 


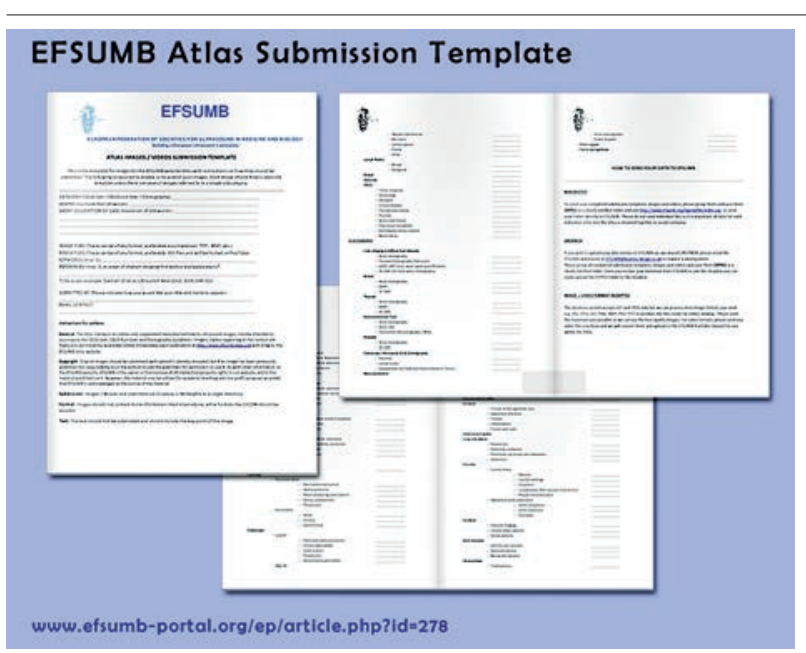

Fig 3. Atlas Submission template

systems. It is of utmost importance, therefore, to illustrate, by pictures and video clips, how the elastographic information is obtained and how the results are displayed according to the various modalities and indications for the elastography use, as reported in greater detail in Part 1 and Part 2 of the EFSUMB Recommendations on the Clinical Use of Ultrasound Elastography 2012 [10,11]. The illustrations are primarily indexed according to the organs to be investigated as listed in the Guidelines (liver, breast, thyroid, GI Tract, prostate, EUS and musculoskeletal) and secondly according to the modality of investigation, as appropriate (e.g. Strain Elastography=SE, Shear Wave Elastography $=$ SWE, point Shear Wave Elastography $=$ pSWE, Transient Elastography $=$ TE, etc).

\section{All in one, the educational portal}

The Educational Portal (EP) was considered necessary to host the accumulated material on the main EFSUMB website. By offering a category menu, with subcategories in some topics, searches can be specific and refined with the detailed key word search option. The portal offers the option to rate articles, email to a friend or print the article as well as the facility to add comments, date of posting and record the number of times each article is viewed. This is particularly helpful to EFSUMB to gauge the interest in topics and direct limited resources more appropriately.

In addition there is a list of related articles and the option to ask a question of the author. Hosting mp4 videos on YouTube is free, well tested and encoded in different quality levels offering reduced resolution for mobile phones. The advantage of YouTube is that the material is uploaded, converted and easily downloaded.

\section{Committees}

\section{PUBLICATION COMMITTEE}

The main tasks of the PUBLICATION COMMITTEE are

- To advise the Board of Directors on the publication of books, journals and other material in the field of Ultrasound in Medicine.

- To advise on obtaining Commercial sponsorship for any publication activities.

- To advise on advertising of the Federation's publications and, where relevant, obtaining advertisements within these publications.

- To advise on matters concerning the policy for and publication of the European Journal of Ultrasound, in consultation with the Editor and Advisory Editors of the Journal.

- To advise on candidate(s) for the post of Editor of the Journal and on the reinstatement or succession of the Editor, in consultation with the commercial publishers of the Journal.

- To produce the EFSUMB Newsletter for inclusion in the Journal with the Newsletter Editor.

- To produce the Case of the Month for the website and source translations.

- To advise on the development of the EFSUMB website, Atlas and Educational Portal.

EDUCATION AND PROFESSIONAL STANDARDS COMMITTEE

The main tasks of the EDUCATION AND PROFESSIONAL STANDARDS COMMITTEE are

- To establish links with other National and International committees with similar interests.

- To invite the member Societies of the Federation to submit to the committee an analysis of training and accreditation in their own country with a view to harmonization of these courses.

- To invite the member Societies of the Federation to submit student ultrasound education training methods for analysis and recommendation of standardized levels in Europe.

- To advise the Executive Bureau on the minimum training required for competence in the different specialty areas of Medical Ultrasound.

- To advise on the minimum level of activity required to maintain professional competence.

- To advise on the need for and, where relevant, the methods of accreditation of expertise to practice ultrasound in the different specialty areas.

- To advise on the establishment of EFSUMB Learning Centers in Ultrasound (ELC).

- To advise on quality control procedures.

- To plan, initiate and monitor international cooperative studies on training in Medical Ultra- 
sound such as the EFSUMB Common Courses (ECC).

- To propose and formulate scientific sessions on all aspects of ultrasound training and accreditation for inclusion in the EUROSON Congresses.

- To approve Euroson Schools and Endorsed Courses as necessary to promote ultrasound education.

EUROPEAN COMMITTEE FOR MEDICAL ULTRASOUND SAFETY

The main tasks of ECMUS are

- To liaise with the safety committees of WFUMB, AIUM and any other relevant committees.

- To re-examine the EFSUMB Safety Statement annually, or in the light of new scientific findings.

- Reviewing safety statements, literature reviews and tutorials for the website.

- Organising a safety session to take place at the EUROSON Congress on topical issues.

- Producing safety information such as the PowerPoint presentation which will be available on the website and for the use of Euroson Schools and Courses.

- To advise on the minimum technical specification of the equipment required to practice ultrasound in the different specialty areas.

\section{Some general aspects \\ Intellectual property rights}

EFSUMB is the owner or the licensee of all intellectual property rights in our website, and in the material published on it. Those works are protected by copyright laws and treaties around the world. All such rights are reserved. Our status, and that of any identified contributors, as the editors and authors of material on our site, must always be acknowledged. You may print off one copy, and may download extracts, of any page(s) from our website for your personal reference and you may draw the attention of others within your organisation to material posted on our site. You must not modify the paper or digital copies of any materials you have printed off or downloaded in any way, and you must not use any illustrations, photographs, video or audio sequences or any graphics separately from any accompanying text. You must not use any part of the materials on our site for commercial purposes without obtaining permission to do so from us.

Benefits of EFSUMB Membership

- A Europe wide Ultrasound Federation which encourages networking between ultrasound professionals of all disciplines throughout Europe, allowing them to benefit from the wealth of experience and knowledge from other countries and other health-care systems.
- The annual EUROSON meetings which provide a unique opportunity to meet with practitioners from other European countries, to hear talks given by many international experts, to present exciting new data to colleagues from across Europe, and to become involved in ultrasound science, education, research, teaching and politics at a supranational level

- The ability to influence Ultrasound issues on a worldwide basis through our membership of the World Federation for Ultrasound in Medicine and Biology.

- Euroson schools which provide high-level ultrasound education in diverse parts of Europe.

- The Publication Committee ensures that the membership is kept up-to-date with the affairs of EFSUMB via the Newsletter and website publications.

- EPSC - the Education and Professional Standards Committee considers all aspects of medical ultrasound education and professional development throughout Europe, and publishes recommendations on a variety of matters such as minimum standards of training.

- ECMUS - the European Committee for Medical Ultrasound Safety, which takes a lead in keeping the membership up-to-date with all aspects of medical ultrasound safety, and provides expert considered views through the publication of statements on ultrasound safety.

- The EFSUMB Course Book is a valuable resource available free of charge on the website written by experts, beautifully illustrated and leading the teaching of ultrasound internationally.

- The Student Edition of the ECB will be a comprehensive essential tool for all students subsidised by EFSUMB to help standardise European ultrasound teaching and assist students to practice high level ultrasonography, with prompt diagnosis, reduced costs and benefits for patients and the community.

- The Scientific Corner on the EFSUMB website will be developed as a forum for sharing, promoting and collecting data for important areas of research and topics such as the paediatric use of CEUS.

- The EFSUMB Guidelines, which are widely cited, have helped to increase the impact factor of the EJU to from 2.103 in 2006 to 3.260 in 2010 and to the highest figure yet reached 4.116 in 2012 making the EJU the highest ranking ultrasound journal.

'Building a European Ultrasound Community' is our slogan. EFSUMB aims to develop international partner- 
ships and friendships, learning from one another and sharing the best practice from all around Europe. Most importantly, we want to be responsive to our members' needs so we invite you to keep us informed at efsumb@ efsumb.org.

\section{References}

1. Rott HD. EFSUMB statement on the clinical safety of ultrasound diagnosis. Ultraschall Med 1996; 17: 257-258.

2. Rott HD. EFSUMB tutorial: thermal and mechanical indices. Ultraschall Med 1998; 19: 92-95.

3. Duck FA. EFSUMB reviews of recent safety literature. European committee for medical ultrasound safety (ECMUS). Eur J Ultrasound 2000; 11: 151-154.

4. Duck FA. EFSUMB reviews of safety literature: Recent epidemiology papers: European Committee for Medical Ultrasound Safety (ECMUS). Eur J Ultrasound 2001; 13: 227-231.

5. Salvesen KA. EFSUMB: safety tutorial: epidemiology of diagnostic ultrasound exposure during pregnancy-European committee for medical ultrasound safety (ECMUS). Eur J Ultrasound 2002; 15: 165-171.

6. Albrecht T, Blomley M, Bolondi L, et al. Guidelines for the use of contrast agents in ultrasound. January 2004. Ultraschall Med 2004; 25: 249-256.

7. ter Haar G. Bubble trouble? Ultraschall Med 2008; 29: 550551.

8. Terslev L, Hammer HB, Torp-Pedersen S, et al. EFSUMB Minimum Training Requirements for Rheumatologists Performing Musculoskeletal Ultrasound. Ultraschall Med 2013 Jun 17. DOI 10.1055/s-0033-1335143.

9. Claudon M, Cosgrove D, Albrecht T, et al. Guidelines and good clinical practice recommendations for contrast enhanced ultrasound (CEUS) - update 2008. Ultraschall Med 2008; 29: 28-44.

10. Cosgrove D, Piscaglia F, Bamber J, al. EFSUMB Guidelines and Recommendations on the Clinical Use of Ultrasound Elastography.Part 2: Clinical Applications. Ultraschall Med 2013; 34: 238-253.

11. Bamber J, Cosgrove D, Dietrich CF, et al. EFSUMB guidelines and recommendations on the clinical use of ultrasound elastography. Part 1: Basic principles and technology. U1traschall Med 2013; 34: 169-184.

12. Claudon M, Dietrich CF, Choi BI, et al. Guidelines and good clinical practice recommendations for contrast enhanced ultrasound (CEUS) in the liver--update 2012: a WFUMBEFSUMB initiative in cooperation with representatives of AFSUMB, AIUM, ASUM, FLAUS and ICUS. Ultraschall Med 2013; 34: 11-29.

13. Piscaglia F, Nolsoe C, Dietrich CF, et al. The EFSUMB Guidelines and Recommendations on the Clinical Practice of Contrast Enhanced Ultrasound (CEUS): update 2011 on non-hepatic applications. Ultraschall Med 2012; 33: 33-59.
14. Dietrich CF, Averkiou MA, Correas JM, Lassau N, Leen E, Piscaglia F. An EFSUMB introduction into Dynamic Contrast-Enhanced Ultrasound (DCE-US) for quantification of tumour perfusion. Ultraschall Med 2012; 33: 344-351.

15. Barreiros AP, Piscaglia F, Dietrich CF. Contrast enhanced ultrasound for the diagnosis of hepatocellular carcinoma (HCC): comments on AASLD guidelines. J Hepatol 2012; 57: 930-932.

16. Dietrich CF. Comments and illustrations regarding the guidelines and good clinical practice recommendations for contrast-enhanced ultrasound (CEUS)--update 2008. Ultraschall Med 2008; 29 Suppl 4: S188-S202.

17. Dietrich CF, Schreiber-Dietrich D, Hocke M. Comments on the EFSUMB non-liver Guidelines 2011. Praxis (Bern 1994 ) 2012; 101: 1175-1181.

18. Dietrich CF, Cui XW, Boozari B, Hocke M, Ignee A. Contrast-enhanced ultrasound (CEUS) in the diagnostic algorithm of hepatocellular and cholangiocellular carcinoma, comments on the AASLD guidelines. Ultraschall Med 2012; 33 Suppl 1: S57-S66.

19. Dietrich CF, Cui XW, Schreiber-Dietrich DG, Ignee A. EFSUMB guidelines 2011: comments and illustrations. Ultraschall Med 2012; 33 Suppl 1: S11-S21.

20. Sporea I, Badea R, Martie A, et al. Contrast enhanced ultrasound for the characterization of focal liver lesions. Med Ultrason 2011; 13: 38-44.

21. Lencioni R. Impact of European Federation of Societies for Ultrasound in Medicine and Biology (EFSUMB) guidelines on the use of contrast agents in liver ultrasound. Eur Radiol 2006; 16: 1610-1613.

22. Dietrich CF, Cui XW, Barreiros AP, Hocke M, Ignee A. EFSUMB guidelines 2011: comment on emergent indications and visions. Ultraschall Med 2012; 33 Suppl 1: S39-S47.

23. Cui XW, Ignee A, Jedrzejczyk M, Dietrich CF. Dynamic Vascular Pattern (DVP), a Quantification Tool for Contrast Enhanced Ultrasound. Z Gastroenterol 2013; 51: 427-431.

24. Rubaltelli L. EFSUMB Newsletter meets Italy. Interview by Michael Bachmann Nielsen. Ultraschall Med 2008; 29: 323.

25. Gilja OH. EFSUMB Newsletter meets Norway (interview by Professor Michael Bachmann Nielsen). Ultraschall Med 2009; 30: 413.

26. EFSUMB Newsletter meets Turkey. Ultraschall Med 2008; 29: 553-554.

27. Dietrich C.F. Cases of the Month (EFSUMB website). www efsumb org 2008.

28. Sidhu PS. Cases of the Month (EFSUMB website). www efsumb org 2011.

29. Berzigotti A, Piscaglia F. Ultrasound in portal hypertension--part 1. Ultraschall Med 2011; 32: 548-568.

30. Berzigotti A, Piscaglia F; EFSUMB Education and Professional Standards Committee. Ultrasound in portal hypertension--part 2--and EFSUMB recommendations for the performance and reporting of ultrasound examinations in portal hypertension. Ultraschall Med 2012; 33: 8-32. 
31. Dietrich C.F. EFSUMB Course Book. London: European Federation of Societies for Ultrasound in Medicine and Biology, 2013.

32. Dietrich CF. Echtzeit-Gewebeelastographie. Anwendungsmöglichkeiten nicht nur im Gastrointestinaltrakt. Endoskopie Heute 2010; 23: 177-212.
33. Mostbeck G. Elastography - and nobody will come! Ultraschall Med 2013; 34: 211-213.

34. Dietrich CF, Cantisani V. Current status and perspectives of elastography. Eur J Radiol 2013 Mar 26. DOI:pii: S0720048X(13)00116-2. 10.1016/j.ejrad.2013.02.028. 